\title{
Cure and mechanical properties of recycled NdFeB-natural rubber composites
}

\author{
P SARAMOLEE ${ }^{\dagger}$, P LERTSURIWAT ${ }^{\dagger}$, A HUNYEK and C SIRISATHITKUL* \\ Magnet Laboratory, School of Science, ${ }^{\dagger}$ Material Sciences and Engineering Program, \\ School of Engineering and Resources, Walailak University, Nakon Si Thammarat 80161, Thailand
}

MS received 18 May 2009; revised 18 June 2009

\begin{abstract}
Magnetic polymer composites containing recycled neodymium-iron-boron (NdFeB) powder and natural rubber (NR) were prepared by the two-roll mill technique. Their mechanical and cure properties were studied as a function of $\mathrm{NdFeB}$ loading from 0-120 phr. With increasing magnetic loading, the cure time of the NdFeB-NR composites were exponentially decreased because of the reduction of the polymer chain crosslink. The tensile strength of the NR compound, related to the cure characteristics, was reduced by $40 \%$ by the addition of $10 \mathrm{phr} \mathrm{NdFeB}$ fillers because of the inhibition of the stress-induced crystallization. However, the variation in loading from 30-90 phr has modest effects on the tensile strength as well as elongation at break and the hardness. Furthermore, recycled NdFeB-NR composites had higher modulus and lower percentage of swelling in this magnetic loading regime. Simple tests confirmed the distribution of magnetic stray field around pieces of $\mathrm{NdFeB}-\mathrm{NR}$ composites.
\end{abstract}

Keywords. Magnetic polymer composites; neodymium iron boron; natural rubber; cure time; tensile test.

\section{Introduction}

Rubber-ferrite composite is a kind of magnetic polymer composite that can be used as flexible magnets and microwave shields. Several types of elastomers such as natural rubber (NR), butyl rubber (IIR), and acrylonitrile butadiene rubber (NBR) have been tested as polymer matrix for ferrite fillers (Anantharaman et al 2001; Dishovsky et al 2001; Malini et al 2001, 2003; Mohammed et al 2002; Makled et al 2005). Nickel-zinc ferrite $\left(\mathrm{Ni}_{1-x} \mathrm{Zn}_{x} \mathrm{Fe}_{2} \mathrm{O}_{4}\right.$ or NZF) and manganese-zinc ferrite $\left(\mathrm{Mn}_{1-x} \mathrm{Zn}_{x} \mathrm{Fe}_{2} \mathrm{O}_{4}\right.$ or MZF) in NR and IIR matrix were prepared and their magnetic and dielectric parameters could be written as a function of ferrite loading (Anantharaman et al 2001). The studies on MZF-NR (Mohammed et al 2002) and NZF-NR composites (Malini et al 2001, 2003) showed that the tensile strength of NR compounds was greatly reduced by the introduction of $30 \mathrm{phr}$ magnetic fillers but was not largely decreased by the additional loading up to $120 \mathrm{phr}$. It was also suggested that the dependence of cure characteristics and mechanical properties on the magnetic loading were correlated (Malini et al 2001, 2003). For hard magnetic polymer composites, barium ferrite $\left(\mathrm{BaFe}_{12} \mathrm{O}_{19}\right)$ or strontium ferrite $\left(\mathrm{SrFe}_{12} \mathrm{O}_{19}\right)$ have been used as fillers. Barium ferrite-NR composites prepared by the two-roll mill technique possessed large

*Author for correspondence (schitnar@wu.ac.th)
$(\mathrm{BH})_{\max }$ but the tensile strength was reduced with increasing magnetic loading (Makled et al 2005). Like soft ferrites, hard ferrites also acted as non-reinforced fillers inhibiting the stress-induced crystallization in rubbers. In another report, hard ferrite-NBR composites had a higher bound rubber content and a lower equilibrium swelling degree compared to soft magnetic rubber composites (Dishovsky et al 2001).

Compared to hard ferrites, neodymium-iron-boron $(\mathrm{NdFeB})$ is a hard magnetic material with larger $(\mathrm{BH})_{\max }$. Currently, it is widely used in hard disk drives and high efficiency motors. NdFeB can be fabricated in the form of polymer bonded magnets using flexible or rigid polymer as binder materials (Hamano 1995; Dobrzanski and Drak 2004, 2006). Advantages of these polymer reinforced $\mathrm{NdFeB}$ magnets are inexpensive, high dimensional preciseness, processability of complex shapes and unconventional anisotropy. In addition, it was demonstrated that $\mathrm{NdFeB}$ can be used as fillers in thermoplastic, elastomer and thermosetting polymers (Kokabi et al 2005). Our work is aimed to explore the possibility of making magnetic polymer composite from recycled $\mathrm{NdFeB}$ magnets obtained from electronic wastes. NR is chosen as a polymer matrix because of local availability and production of rubber composites certainly increases its value and enhance its applications. In this paper, cure and mechanical properties of recycled $\mathrm{NdFeB}-\mathrm{NR}$ composites are reported. 
Table 1. Formulation of the mixes for preparing NdFeB-NR composites.

\begin{tabular}{lcccccc}
\hline & \multicolumn{6}{c}{ Sample (phr; part per hundred rubber) } \\
\cline { 2 - 7 } Ingredient & $\mathrm{A}$ & $\mathrm{B}$ & $\mathrm{C}$ & $\mathrm{D}$ & $\mathrm{E}$ & $\mathrm{F}$ \\
\hline NR (ADS) & 100 & 100 & 100 & 100 & 100 & 100 \\
Stearic acid & 1 & 1 & 1 & 1 & 1 & 1 \\
ZnO & 5 & 5 & 5 & 5 & 5 & 5 \\
ZMP & 1 & 1 & 1 & 1 & 1 & 1 \\
CBS & $0 \cdot 6$ & 0.6 & $0 \cdot 6$ & 0.6 & 0.6 & 0.6 \\
Sulphur & 1.5 & 1.5 & 1.5 & 1.5 & 1.5 & 1.5 \\
NdFeB & 0 & 10 & 30 & 60 & 90 & 120 \\
\hline
\end{tabular}

CBS, N-Cyclohexyl-2-benzothiazole sulfonamide; ZMP, polymerized, stearic hindered polyphenol

\section{Experimental}

\subsection{Preparation and characterization of $N d F e B$ powders}

Bars of $\mathrm{NdFeB}$ magnets were obtained from electronic wastes. After the removal of protective layer, they were broken into smaller bits and milled in a ball milling machine (Retsch PM100) at $300 \mathrm{rpm}$ for $1 \mathrm{~h}$. After milling, selected $\mathrm{NdFeB}$ powders were suspended in 1-butanol in order to measure their size distribution by a laser particle size analyzer (Coulter LS230).

\subsection{Mixing $\mathrm{NdFeB}$ with NR sheet}

An air dried sheet of natural rubber was cut into pieces. Pieces of compound rubber with different $\mathrm{NdFeB}$ loading and other additives listed in table 1 were prepared by the two-roll mill technique. A control sample $(A)$ was also produced without any magnetic fillers. After their curing properties were measured according to ASTM D20842000 standard by an oscillating disc rheology meter (Gotech GT-7070-S2), samples were hot pressed in a compression mould.

\subsection{Characterizations of composites}

Pressed surfaces of the composites were inspected by an optical microscope. The tensile test was performed according to ASTM D412-2000 standard using a universal testing machine and the hardness (shore A, ASTM D2240-86) was measured by a hardness tester (Bareiss, Digitest). For an ASTM D471-98 standard swelling test, $10 \times 10 \times 2 \mathrm{~mm}^{3}$ samples were immersed in a closed container filled with $30 \mathrm{ml}$ toluene for $166 \mathrm{~h}$. The weights of samples before $\left(W_{0}\right)$ and after $\left(W_{\mathrm{s}}\right)$ immersion were used to compute the percentage of swelling.

$$
\text { Swelling }(\%)=100 \times\left(W_{\mathrm{s}}-W_{0}\right) / W_{0} \text {. }
$$

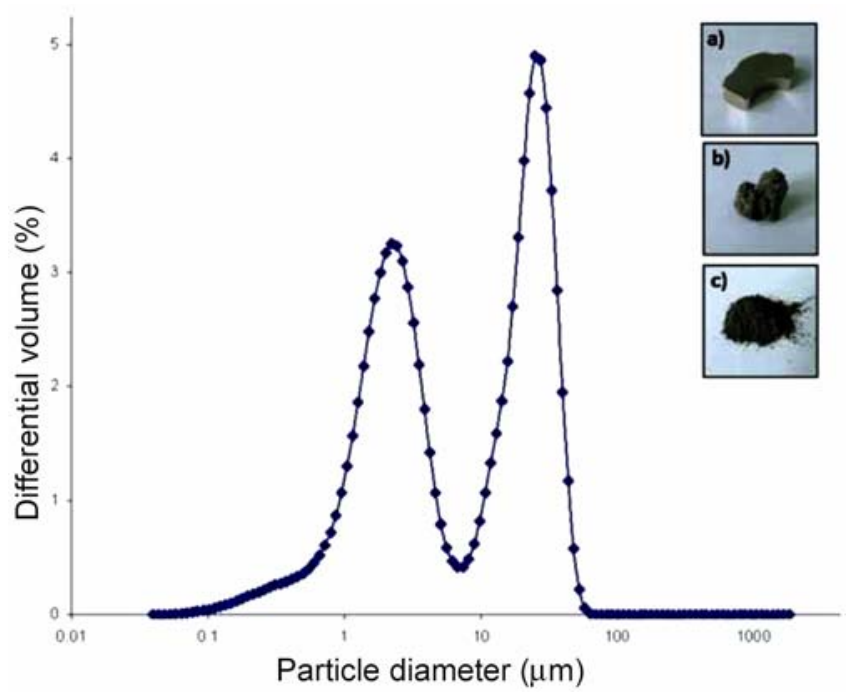

Figure 1. Particle size distribution of $\mathrm{NdFeB}$ powders after milling for $1 \mathrm{~h}$. Insets are photographs of the magnets at 3 different stages: (a) from electronic wastes, (b) after broken and (c) after milling.

Magnetic behaviour was tested by measuring stray field from the composites with a Hall effect gaussmeter (Lakeshore 450). By moving the probe around $33.5 \times 14.5 \times$ $1.5 \mathrm{~mm}^{3}$ samples, their maximum fields were recorded and compared.

\section{Results and discussion}

The size distribution of $\mathrm{NdFeB}$ powders in figure 1 shows bimodal peaks. Smaller clusters are about $2.208 \mu \mathrm{m}$ in diameter and larger clusters around $24.95 \mu \mathrm{m}$ have a higher volume fraction and a narrower size distribution. When these $\mathrm{NdFeB}$ clusters are embedded in the rubber matrix, they can be inspected by an optical microscope. In figure 2(a), the control sample without magnetic fillers has a smooth pressed surface. In the case of NdFeB-NR 
composites as exemplified in figure 2(b), the surfaces look rough and some pits are clearly visible due to chunky clusters whose size corresponds to the distribution in figure 1. Figure 2(b) also implies that significant amounts of air bubbles and voids are formed during the process.

Both scorch time and cure time of NdFeB-NR composites, plotted as a function of $\mathrm{NdFeB}$ loading in figure 3, sharply decreased with initial loading. The trend, similar to those found in magnetic rubber composites (Malini et al 2001, 2003; Sasikumar et al 2006), confirms the effect of fillers on the chain crosslink process. In addition, certain metals have the catalytic effect on the sulphur cure reaction (Sasikumar et al 2006). The cure time seems to saturate in a high loading regime, indicating that the time of vulcanization process cannot be further speeded up. On the other hand, the scorch time, indicating the time of processability, steadily dropped even at loading up to $120 \mathrm{phr}$.
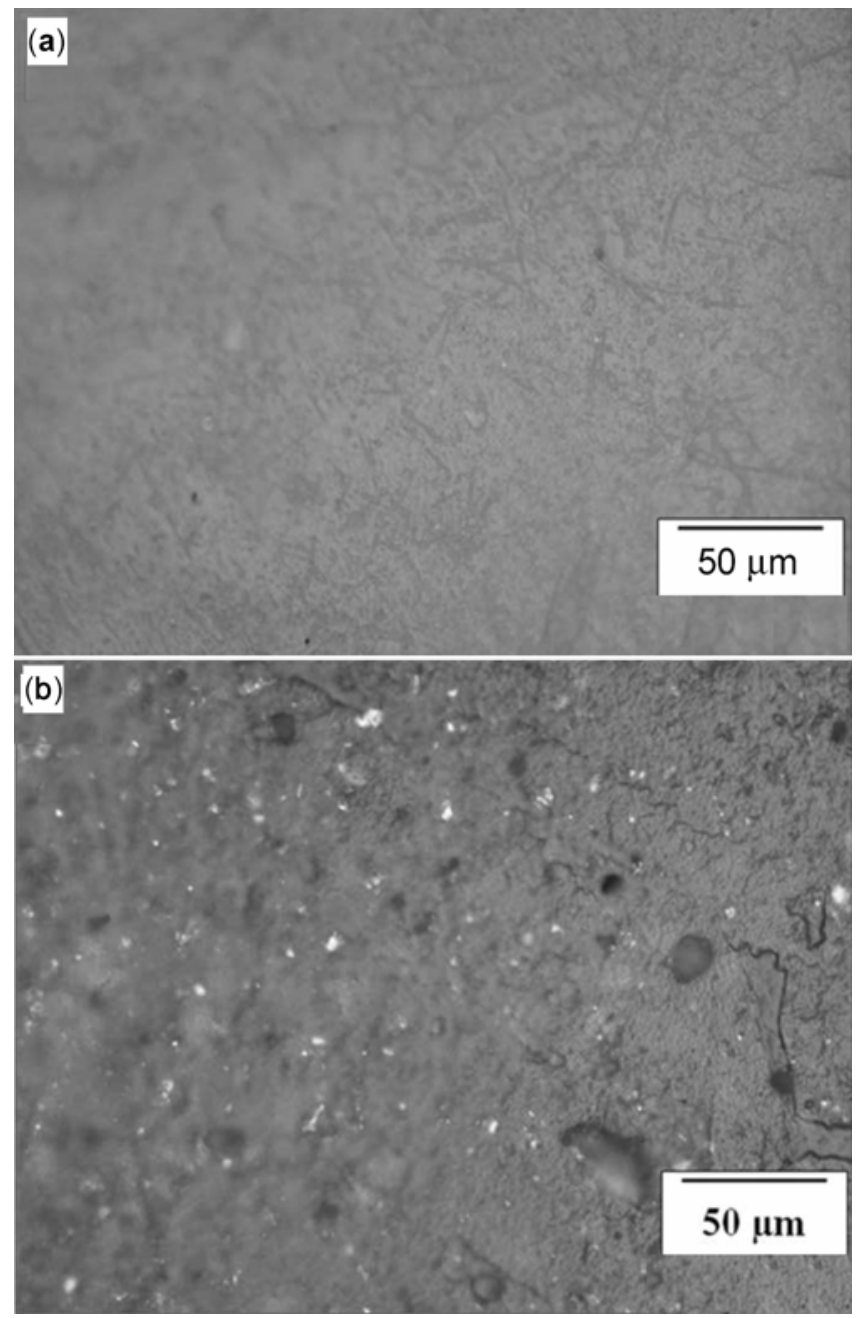

Figure 2. Morphology of the pressed surface of the rubber compounds: (a) without magnetic fillers and (b) with $120 \mathrm{phr}$ NdFeB loading.
Minimum torque, corresponding to a shear force acting on the composites before complete vulcanization, is related to a viscosity. Typically, the viscosity of rubber compounds depends on the time of mixing and the type of filler (Sperling 2006). If the compound takes a long time to mix, its viscosity of rubber compound decreased due to the shear force supplied by the two rollers. If the fillers reinforce or bond to the rubber molecules, the viscosity of rubber compound is increased. In this experiment, each rubber formula takes a relatively short time to evenly mix so the dominant factor to influence the viscosity is the type of filler. The viscosity of NR compounds decreased because the $\mathrm{NdFeB}$ powder does not reinforce the rubber. Moreover, the viscosity is related to molecular weight and entanglement of molecular chains. The addition of magnetic fillers reduces the entanglements and thus the viscosity.

Maximum torque, the value that occurs after the rubber compound is completely vulcanized, indicates the modulus of rubber after the crosslink. In figure 4, the maximum torque and hence the modulus of rubber compounds initially decreased when the loading was $10 \mathrm{phr}$ but then

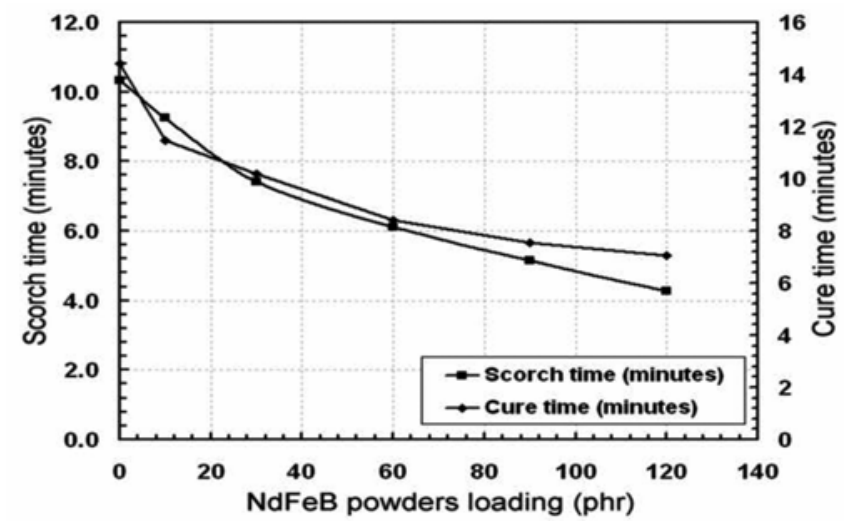

Figure 3. Cure time and scorch time of NdFeB-NR composites with different magnetic loadings.

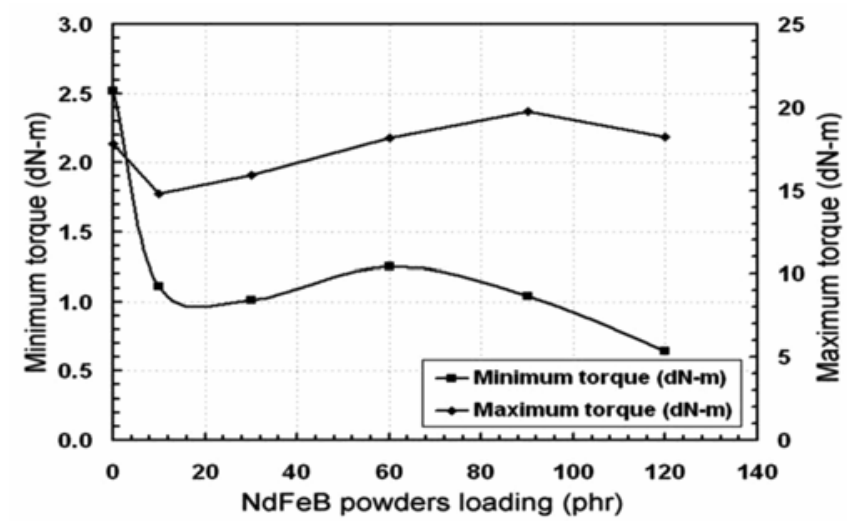

Figure 4. Maximum and minimum torques of $\mathrm{NdFeB}-\mathrm{NR}$ composites with different magnetic loadings. 
Table 2. Mechanical and magnetic properties of NdFeB-NR composites with different magnetic loadings.

\begin{tabular}{rcccc}
\hline NdFeB (phr) & $\begin{array}{c}\text { Tensile } \\
\text { strength }(\mathrm{MPa})\end{array}$ & $\begin{array}{c}\text { Elongation } \\
\text { at break }(\%)\end{array}$ & $\begin{array}{c}\text { Hardness } \\
(\text { shore A) }\end{array}$ & $\begin{array}{c}\text { Maximum } \\
\text { stray field }(G)\end{array}$ \\
\hline 0 & $13 \cdot 767$ & 705 & 33 & $0 \cdot 604$ \\
10 & $8 \cdot 384$ & 650 & 32 & 23.855 \\
30 & $7 \cdot 288$ & 622 & 31 & 36.915 \\
60 & $7 \cdot 425$ & 645 & 30 & 49.472 \\
90 & $7 \cdot 435$ & 618 & 30 & 42.675 \\
120 & $4 \cdot 375$ & 600 & 23 & 53.889 \\
\hline
\end{tabular}

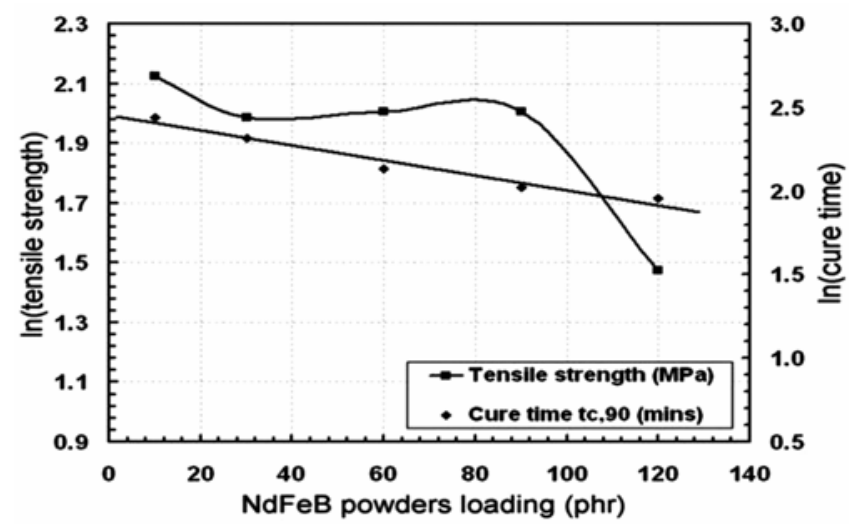

Figure 5. Logarithmic plots of cure time and tensile strength with different magnetic loadings.

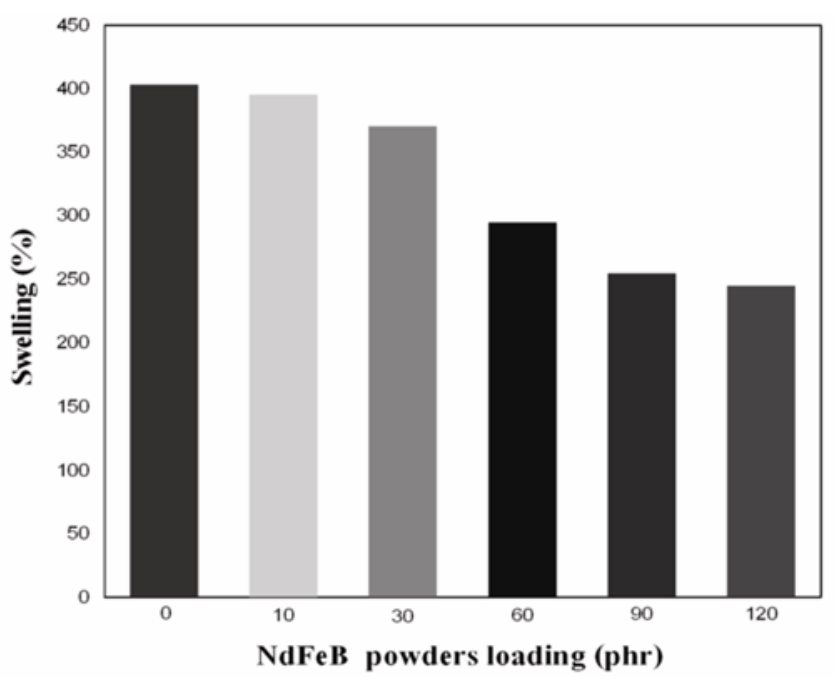

Figure 6. Percentage of swelling by $\mathrm{NdFeB}-\mathrm{NR}$ composites with different magnetic loadings.

increased when the loading was higher. The increase in the maximum torque with increasing magnetic loading from 10 to $90 \mathrm{phr}$, agreed with the results in NZF-NR composites (Malini et al 2001, 2003), and is due to the increase in the stiffness of the composites by the variation of magnetic fillers in this loading regime without significant effects on other mechanical properties.
The tensile strength, the elongation at break and the hardness of $\mathrm{NdFeB}-\mathrm{NR}$ composites, shown in table 2, decreased with the increase in magnetic loading. By the addition of $10 \mathrm{phr} \mathrm{NdFeB}$ fillers, the tensile strength of the NR compound reduced by $40 \%$ since the fillers inhibit the orientation to form crystallite. The trends of tensile strength and elongation at break are similar to the reports on soft ferrite-NR composites (Malini et al 2001, 2003; Mohammed et al 2002) by reaching modest values at the magnetic loading of $30 \mathrm{phr}$ and remaining insensitive to the loading up to $90 \mathrm{phr}$. At $120 \mathrm{phr}$, our results differ from those of soft ferrite-NR composites (Malini et al 2001, 2003; Mohammed et al 2002) but resembles those of barium ferrite-NR composites (Makled et al 2005) by exhibiting drops in tensile properties. Having been prepared by the two-roll mill technique with hard magnetic powder as fillers, these barium ferrite-NR composites and our samples have the lowest elongation at break and tensile strength at the maximum magnetic loading. The variation of hardness with the $\mathrm{NdFeB}$ and barium ferrite, though, shows an opposite trend. Still, the change in the 30 to $90 \mathrm{phr}$ regime is marginal. The rule of mixtures has been tested and modified to predict the change in properties of polymer due to fillers. In the modified rule of mixtures incorporating defects, the tensile strength is reduced by the factor of $e^{-k d}$, where $k$ is a constant and $d$ a defect concentration (Sarkar 1998). In our case, defects should increase with increasing magnetic loading. As shown in the logarithmic plots against the magnetic loading in figure 5, the cure of time can be linearly fitted whereas the tensile strength does not follow a straight line. This implies that several other factors also have influence on the tensile strength of the composites making the final value difficult to predict.

Results from the magnetic field measurement in table 2 show that the maximum stray field is generally increased with the amount of $\mathrm{NdFeB}$ fillers. Finally, the percentage of swelling in non-polar solvents such as toluene in figure 6 is reduced by the introduction of $\mathrm{NdFeB}$ fillers into the NR matrix. Since figure 1 suggests that substantial gaps and voids exist in NdFeB-NR composites, this decrease is likely attributable to the increase in the weight of composites by the addition of metals. 


\section{Conclusions}

Permanent NdFeB magnets can be recycled in the fabrication of magnetic polymer composites. Since the NdFeBNR composites retain magnetic behaviours, they can be implemented as light and flexible permanent magnets. However, the introduction of $\mathrm{NdFeB}$ fillers affects the cure and mechanical properties of the NR matrix. The reduction of the tensile strength is partly related to the exponential decay in the cure time by the magnetic loading because the non-reinforced $\mathrm{NdFeB}$ fillers inhibit the stress-induced crystallization. Nevertheless, the tensile strength, the elongation at break and the hardness are rather constant when the fillers are increased from 30-90 phr. In this regime, the modulus and the resistance to swelling of $\mathrm{NdFeB}-\mathrm{NR}$ composites are also improved.

\section{Acknowledgements}

This work was financially supported by Walailak University's research unit fund. The samples were prepared at Rajamangala University of Technology Srivijaya, Saiyai campus.

\section{References}

Anantharaman M R, Malini K A, Sindhu S, Mohammed E M, Date S K, Kulkarni S D, Joy P A and Kurian P 2001 Bull. Mater. Sci. 24623

Dishovsky N, Ruskova K and Radulov I 2001 Mater. Res. Bull. 3635

Dobrzanski L A and Drak M 2004 J. Mater. Process. Tech. 157-158 650

Dobrzanski L A and Drak M 2006 J. Mater. Process. Tech. 175149

Hamano M 1995 J. Alloy. Compd. 2228

Kokabi M, Arabgol F and Manteghian M 2005 Iran. Polym. $J .1471$

Malini K A, Mohammed E M, Sindhu S, Joy P A, Date S K, Kulkarni S D, Kurian P and Anantharaman M R 2001 J. Mater. Sci. 365551

Malini K A, Kurian P and Anantharaman M R 2003 Mater. Lett. 573381

Makled M H, Matsui T, Tsuda H, Mabuchi H, El-Mansy M K and Morii K 2005 J. Mater. Process. Tech. 160229

Mohammed E M, Malini K A, Kurian P and Anantharaman M R 2002 Mater. Res. Bull. 37753

Sarkar B K 1998 Bull. Mater. Sci. 21329

Sasikumar K, Suresh G, Thomas K A, John R, Natarajan V, Mukundan T and Vishnubhatla R M R 2006 Bull. Mater. Sci. 29637

Sperling L H 2006 Introduction to physical polymer science (Hoboken, New Jersey: Wiley Interscience) 4th ed. 